\title{
Meningococcal disease: changes in epidemiology and prevention
}

This article was published in the following Dove Press journal:

Clinical Epidemiology

18 September 2012

Number of times this article has been viewed

\author{
Qiuzhi Chang' \\ Yih-Ling Tzeng ${ }^{2}$ \\ David S Stephens ${ }^{1-3}$ \\ 'Department of Epidemiology, \\ Rollins School of Public Health, \\ Emory University, ${ }^{2}$ Department of \\ Medicine, Emory University School of \\ Medicine, ${ }^{3}$ Laboratories of Microbial \\ Pathogenesis, Department of Veterans \\ Affairs Medical Center, Atlanta, GA
}

Correspondence: David S Stephens Department of Veterans Affairs Medical Center, Research (I5I-I), 1670 Clairmont Road, Decatur, GA 30033, USA

$\mathrm{Tel}+$ I 4047287688

Fax +I 4043292210

Email dstep0I@emory.edu
Abstract: The human bacterial pathogen Neisseria meningitidis remains a serious worldwide health threat, but progress is being made toward the control of meningococcal infections. This review summarizes current knowledge of the global epidemiology and the pathophysiology of meningococcal disease, as well as recent advances in prevention by new vaccines. Meningococcal disease patterns and incidence can vary dramatically, both geographically and over time in populations, influenced by differences in invasive meningococcal capsular serogroups and specific genotypes designated as ST clonal complexes. Serogroup A (ST-5, ST-7), B (ST-41/44, ST-32, ST-18, ST-269, ST-8, ST-35), C (ST-11), Y (ST-23, ST-167), W-135 (ST-11) and X (ST-181) meningococci currently cause almost all invasive disease. Serogroups B, C, and Y are responsible for the majority of cases in Europe, the Americas, and Oceania; serogroup A has been associated with the highest incidence (up to 1000 per 100,000 cases) and large outbreaks of meningococcal disease in sub-Saharan Africa and previously Asia; and serogroups W-135 and $\mathrm{X}$ have emerged to cause major disease outbreaks in sub-Saharan Africa. Significant declines in meningococcal disease have occurred in the last decade in many developed countries. In part, the decline is related to the introduction of new meningococcal vaccines. Serogroup $C$ polysaccharide-protein conjugate vaccines were introduced over a decade ago, first in the UK in a mass vaccination campaign, and are now widely used; multivalent meningococcal conjugate vaccines containing serogroups A, C, W-135, and/orY were first used for adolescents in the US in 2005 and have now expanded indications for infants and young children, and a new serogroup A conjugate vaccine has recently been introduced in sub-Saharan Africa. The effectiveness of these conjugate vaccines has been enhanced by the prevention of person-to-person transmission and herd immunity. In addition, progress has been made in serogroup B-specific vaccines based on conserved proteins and outer membrane vesicles. However, continued global surveillance is essential in understanding and predicting the dynamic changes in the epidemiology and biological basis of meningococcal disease and to influence the recommendations for current and future vaccines or other prevention strategies.

Keywords: Neisseria meningitidis, meningococcal disease, conjugate vaccines, meningococcal vaccines

\section{Introduction}

Human infections caused by meningococcus (Neisseria meningitidis) remain a serious health problem, infecting 500,000 to 1.2 million people and killing between 50,000 and 135,000 per year worldwide. ${ }^{1}$ Infections due to $N$. meningitidis can present as a spectrum of clinical illness, with meningitis and septicemia being the most common, but also including pneumonia, septic arthritis, pericarditis, conjunctivitis, and urethritis. ${ }^{2}$ Meningococcal meningitis (infection of the subarachnoid space 
involving the meninges and the central nervous system) often presents with fever, rash, meningeal signs (headache, stiff neck), and altered mental status. Deafness or other cranial nerve loss and long-term cognitive disability can also be a consequence. ${ }^{2}$ Meningococcal septicemia is a fulminant infection (sometimes $<24$ hours) with initial symptoms that are nonspecific (fever, muscle aches) and is difficult to diagnose before the onset of a maculopapular, petechial, or purpuric rash. Septicemia can result in rapid onset of hypotension, multiorgan dysfunction shock, peripheral ischemia, limb loss, and death. Overall mortality for invasive meningococcal disease is approximately $10 \%$ of infected individuals, ${ }^{3}$ but is up to $40 \%$ in cases of septicemia.

The diagnosis of meningococcal meningitis is confirmed by cerebrospinal fluid pleocytosis, Gram stain, polymerase chain reaction, culture of cerebrospinal fluid, or cultures of blood or skin lesions. ${ }^{2}$ Diagnosis of other invasive meningococcal disease is based on blood or skin lesion culture or Gram stain, polymerase chain reaction, and culture of normally sterile sites, such as synovial or pericardial fluid. In addition to polymerase chain reaction, rapid tests used to identify $N$. meningitidis based on latex agglutination or chromatography immunodetection have been used. ${ }^{4}$ Early antibiotic treatment with a thirdgeneration cephalosporin, penicillin, or meropenam to stop proliferation of $N$. meningitidis immediately is the primary goal of treating infected individuals. ${ }^{4}$ Due to the potential for contact and epidemic spread, rapid onset, high case-fatality rate, and neurologic sequelae of meningococcal disease, a single case elicits an immediate public health response. Chemoprophylaxis with rifampin, ciprofloxacin, ceftriaxone, or azithromycin to eradicate nasopharyngeal carriage of the meningococcus is recommended for close contacts of patients to protect susceptible individuals and prevent further transmission. ${ }^{5}$ Current prevention measures also include immunization with meningococcal polysaccharide conjugate vaccines directed at one to four meningococcal serogroups, ie, A, C, Y, and $\mathrm{W}-135 .^{5}$ Serogroup B vaccines based on outer membrane vesicles have been used to control serogroup B outbreaks. ${ }^{6-8}$

\section{Changing global epidemiology}

Meningococci are classified according to serologic typing based on the biochemical composition of the capsular polysaccharide. In total, 13 serogroups of $N$. meningitidis have been reported, with $\mathrm{A}, \mathrm{B}, \mathrm{C}, \mathrm{E}, \mathrm{H}, \mathrm{I} / \mathrm{K}, \mathrm{L}, \mathrm{W}-135, \mathrm{X}$, $\mathrm{Y}$ and $\mathrm{Z}$ confirmed genetically. ${ }^{1}$ However, six serogroups (A, B, C, W-135, X, and Y) cause almost all worldwide life-threatening disease. ${ }^{2}$ Genomic typing (eg, multilocus sequence typing) and whole genome comparisons have unlocked a broader understanding of the global epidemiology of meningococcal disease. With multilocus sequence typing, meningococcal isolates are classified into different sequence types based on polymorphisms in seven housekeeping genes considered not to be under selective pressure. ${ }^{9}$

The incidence of meningococcal disease is cyclical in nature, having peaks and troughs every 5-8 years in some epidemiologic settings. ${ }^{10}$ However, disease patterns and incidence vary in populations geographically and over time among the different invasive meningococcal serogroups and sequence type (ST) clonal complexes.

In the US, active bacterial core surveillance is a prospective laboratory and population-based surveillance system that tracks invasive bacterial pathogens including N. meningitidis ${ }^{11,12}$ (Figure 1). The incidence of meningococcal disease in the US in the last quarter century peaked at roughly 1.7 per 100,000 in the mid 1990 s and since has continually declined to 0.35 per 100,000 in $2007 .{ }^{11,12}$ The distribution of serogroups causing disease has also shifted. ${ }^{13}$ Serogroup $\mathrm{C}$ accounted for the majority of cases in the first decade of surveillance. However, the incidence of serogroup $\mathrm{C}$ diminished significantly after 1999 , before the introduction of meningococcal conjugate vaccines. ${ }^{10}$ In comparison, the rates of serogroup B was consistent between 1992 and 2001, but have also declined since 2001. Serogroup Y cases emerged in the mid 1990s and the disease incidence peaked in 1997. Although decreases in serogroup $\mathrm{Y}$ incidence have occurred since 2001 with the overall decline in the incidence of meningococcal disease, serogroup $\mathrm{Y}$ continues to cause disease in the population (Figure 1). Almost all of the serogroup $\mathrm{C}$ and $\mathrm{Y}$ meningococcal disease was caused by the ST-11 complex and ST-23 clonal complexes, respectively, ${ }^{14}$ suggesting that closely related strains circulate in the community and cause sporadic disease.

Serogroup A is associated with the highest incidences of meningococcal disease. In sub-Saharan countries of Africa, extending from Senegal in the west to Ethiopia in the east, known as the African meningitis belt, there have been large periodic epidemics of serogroup A meningococcal disease occurring every $8-10$ years since 1905 , with rates of disease that can exceed 1000 cases per $100,000 .{ }^{10}$ In the last two decades, two ST clonal complexes, ST-5 and ST-7, have been responsible for African meningitis belt outbreaks due to serogroup A. ${ }^{15}$ The patterns in the region are linked to environmental factors, such as climatic changes (dry season, winds of the Harmattan), coinfection, crowding, and specific population susceptibility. ${ }^{16-18}$ 

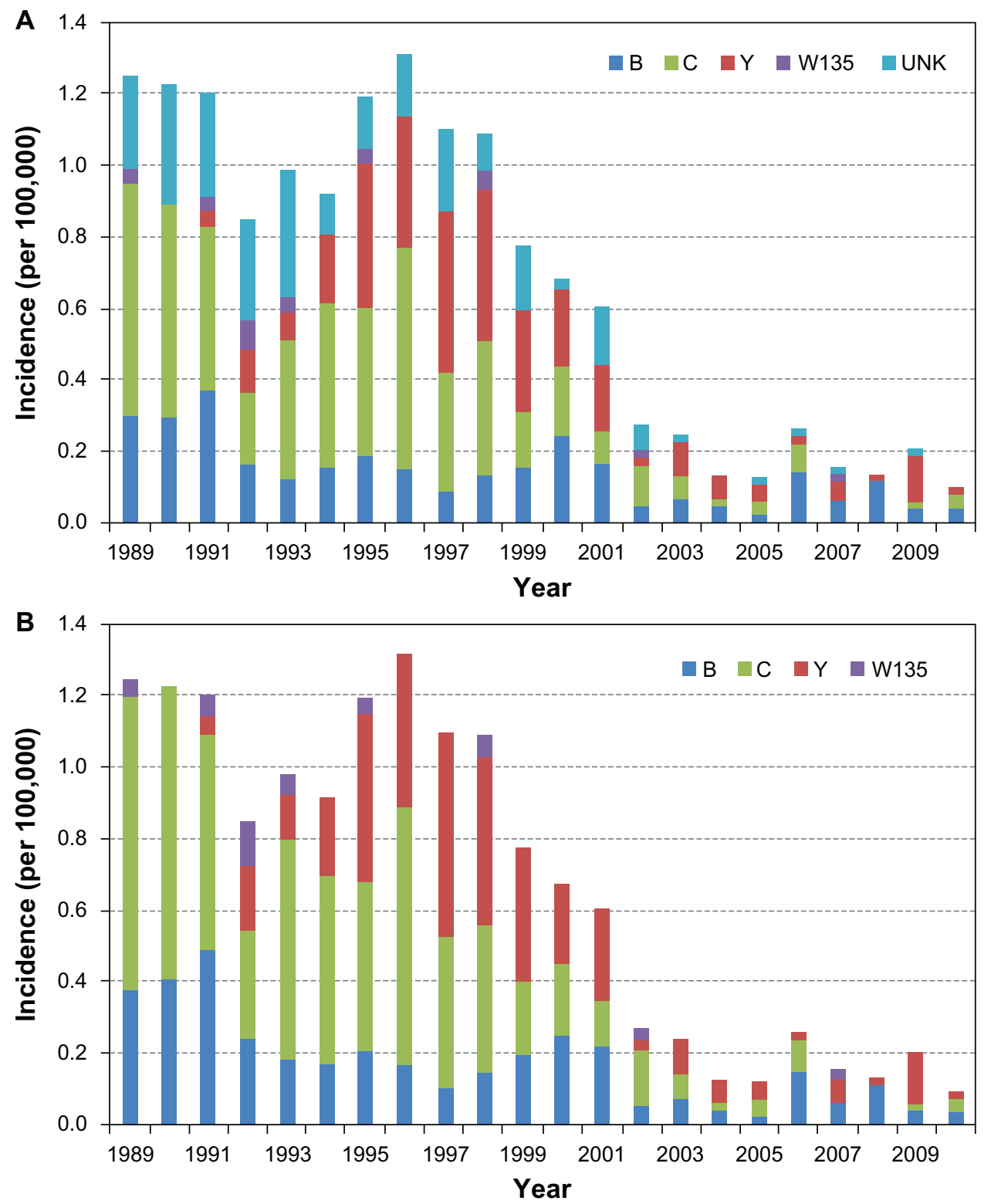

Figure I (A) Active bacterial core surveillance of the incidence of meningococcal disease by serogroups, 1988-2010, Metropolitan Atlanta, GA. (B) Cases with unknown serogroups have been shown to be genetically serogroups $B, C$, and $Y,{ }^{102}$ and thus were imputed by proportionally categorizing into those serogroups.

In the US as well as other industrialized countries, outbreaks of serogroup A disease occurred with similar periodicity during the first part of the 20th century, but disappeared after World War II for unknown reasons. Even though it is now virtually nonexistent in the US and most developed countries, serogroup A meningococcal disease remains a public health threat in sub-Saharan Africa and other areas of the developing world. Over the last two decades, great strides have been made in development of meningococcal conjugate vaccines with the recent successful introduction of a new serogroup A meningococcal conjugate vaccine, MenAfriVac ${ }^{\mathrm{TM}}$ (Serum Institute of India Ltd., Pune, India), in sub-Saharan Africa (see "New vaccines for prevention" section).
Serogroup B meningococcal disease is generally associated with a lower incidence of disease compared with serogroups A and C. However, serogroup B is an important cause of sporadic disease and of prolonged outbreaks in developed countries. In the US, the incidence of serogroup B meningococcal disease has fluctuated, but currently is contributing to $30 \%-40 \%$ of all meningococcal disease. ${ }^{1}$ In the Pacific Northwest (Oregon and parts of Washington State), serogroup B (clonal complex ST-32) caused a prolonged outbreak in 1993-2007..$^{19}$ Curiously, serogroup B disease is now rare in sub-Saharan Africa. There is greater genetic diversity and thus antigenic diversity in serogroup B strains that cause sporadic serogroup B disease compared with other serogroups, with ST-41/44, 
ST-32, ST-18, ST-269, ST-35, and ST-8 causing the majority of serogroup B cases, and a number of other STs are found in collections of serogroup B isolates. ${ }^{20}$ Novel serogroup B strains are occurring worldwide and the diversity of clonal complexes causing serogroup B presents a challenge to control through vaccination. Also, a number of ST-11 isolates, a clonal complex usually associated with serogroup $\mathrm{C}$, express the serogroup B capsule. ${ }^{20}$ As described below, meningococcal "capsule-switching" 21 due to transformation and recombination at the cps locus allows escape of vaccine-induced or natural protective immunity. This escape mechanism has raised concerns about serogroup replacement as a threat to the effectiveness of meningococcal conjugate vaccines. Serogroup B strains are of special concern due to the absence of a vaccine for the routine prevention of serogroup B disease. The serogroup B capsule is poorly immunogenic due to identity with human antigens ${ }^{22}$ and is not a component of meningococcal conjugate vaccines. However, outer membrane vesicles have been developed for control of serogroup B clonal outbreaks. ${ }^{6,23}$ An outer membrane vesicle vaccine helped control a serogroup B outbreak in New Zealand in 2004 and a serogroup B outer membrane protein-containing vaccine, VA-MenGOC-BC ${ }^{\circledR}$ (Finlay Institute, Habana, Cuba), has been extensively used (over 55 million doses) in Cuba and Latin America. ${ }^{7,23-26}$ New approaches based on conserved proteins are in late-stage clinical trials. ${ }^{27-31}$

The other serogroup that accounts for a majority of meningococcal disease cases throughout the world is serogroup C. In the US, serogroup C disease is responsible partly for endemic disease as well as clusters of local outbreaks, accounting for approximately $30 \%$ of overall disease. ${ }^{11,14}$ Increases in serogroup C meningococcal disease were seen in the 1980s and 1990s worldwide, attributed to the spread of a hypervirulent ST-11 complex/ET-37 complex clone. ${ }^{10}$ The meningococcal serogroup $\mathrm{C}$ conjugate vaccine was first introduced in the UK in 1999 to address the growing incidence of disease. The incidence of meningococcal disease decreased by one half from 1999 to 2006 in Europe (following the introduction of serogroup $\mathrm{C}$ conjugate vaccines), but has subsequently stabilized. ${ }^{32}$ As noted above, since the turn of this century, there has been a significant decline in overall meningococcal disease as well as serogroup $\mathrm{C}$ disease in the US. ${ }^{12}$

With periodic exceptions, other serogroups account for less than $10 \%$ of all meningococcal disease. As noted, in parts of the US, serogroup Y emerged in the early 1990s and increased in incidence until the mid to late $1990 \mathrm{~s}$. Serogroup Y increased to almost $50 \%$ of cases in the mid 1990s, but accounted only for $2 \%$ of all meningococcal infections in the early 1990s. ${ }^{33}$ In 1998, a carriage study examining nasopharyngeal specimens from 1818 high school students from hypersporadic counties in the metropolitan area of Atlanta, GA, found the rate of carriage to be $7.7 \%$ and of these, 48\% were serogroup Y. ${ }^{34}$ However, in 2006-2007, a similar carriage study in high school students found a much lower proportion of serogroup Y carriage. ${ }^{35}$ The lower frequency of serogroup $Y$ and overall meningococcal carriage was reflected in a decrease in invasive meningococcal cases between 1998 and 2007. ${ }^{12}$ Serogroup Y disease has also been reported in South America, South Africa, Europe, and Israel. ${ }^{36,37}$ Most of the serogroup Y disease increase is associated with ST-23 and ST-167 clonal complexes. ${ }^{36,38}$ Serogroup X (ST-181) has caused localized outbreaks in certain African countries, including Kenya, Niger, and Ghana, ${ }^{39-43}$ but is rarely seen as a cause of disease outside of Africa. Serogroup W-135 has emerged in the last two decades as a cause of epidemic outbreaks in Hajj pilgrimages and in the African meningitis belt. ${ }^{44,45}$ Outbreaks caused by the spread of W-135 (ST-11) strains closely related to ST-11 serogroup C strains are believed to be in part attributable to capsule switching. ${ }^{46}$

\section{Pathophysiology and natural history}

$N$. meningitidis, a Gram-negative $\beta$-proteobacterium of the family Neisseriaceae, is an exclusive pathogen in humans, carried asymptomatically in the nasopharynx by $5 \%-10 \%$ of adults in nonepidemic periods. It is an aerobic diplococcus and can be either structurally encapsulated or not encapsulated. Capsule polysaccharide expression of the bacteria plays a key role in meningococcal pathogenesis. $N$. meningitidis strains that cause invasive disease are almost always encapsulated, which helps survival of the bacteria during invasive disease and promotes transmission as well as protection from antibodies and phagocytic cells. ${ }^{47}$ With the exception of the serogroup A and X capsules, meningococcal capsular polysaccharides associated with invasive disease are composed of or contain sialic acid units. Serogroups B and C are $(\alpha 2 \rightarrow 8)$-linked and $(\alpha 2 \rightarrow 9)$-linked polysialic acid, respectively, ${ }^{48}$ while serogroups $\mathrm{Y}$ and W-135 are alternating units of $D$-glucose or $D$-galactose and sialic acid, respectively. ${ }^{49}$ The serogroup A capsule is composed of $(\alpha 1 \rightarrow 6)$-linked N-acetyl-mannosamine-1phosphate, ${ }^{50}$ while serogroup $X$ expresses $(\alpha 1 \rightarrow 4)$-linked $\mathrm{N}$-acetyl-D-glucosamine 1-phosphate. ${ }^{51}$ Other properties of the meningococcus that contribute to its virulence are expression of surface adhesive proteins such as pili that 
allow movement (twitching motility) and binding to and passage into epithelial cells, meningococcal endotoxin or lipo-oligosaccharide that binds to TLR-4 and produces acute vascular and cerebrospinal fluid inflammation, and proteins that bind iron as an important growth factor during colonization. ${ }^{1}$

$N$. meningitidis has a dynamic biology in that it undergoes frequent (up to $10^{-3} /$ cell) antigenic variability and escape from vaccine-induced or natural protective immunity. ${ }^{52,53}$ Genetic mechanisms of variability include horizontal gene transfer of DNA sequences, ${ }^{54}$ phase variation through a slipped strand mispairing mechanism, ${ }^{55-57}$ and transposition of mobile elements ${ }^{58}$ that create surface structure variability of the organism, gene conversion, and antigenic variation via homologous recombination ${ }^{21,59-62}$ and regulation by the twocomponent regulatory system. ${ }^{63}$ Capsular switching occurs through horizontal gene transfer, allowing the bacteria to exchange serogroup specific capsule biosynthesis genes and thus change its capsular phenotype..$^{21,54,64-68}$ This mechanism is detected by identifying strains that are genetically related, such as by multilocus sequence typing. Capsular switching is a potential concern for vaccines that do not include protection against all meningococcal serogroups. However, no meaningful increase in meningococcal disease due to other serogroups occurred after the introduction of serogroup $\mathrm{C}$ conjugate vaccines in the UK. ${ }^{69}$

Understanding meningococcal carriage and humanto-human transmission is a key to the understanding of meningococcal epidemiology. Hosted only by humans, transmission of the meningococcus occurs usually through large respiratory droplets from asymptomatic human carriers or individuals who are ill with upper respiratory symptoms. Meningococcal disease occurs usually 1-10 days after acquisition. Asymptomatic nasopharyngeal carriage can be another outcome of transmission and acquisition. Carriage can last for days to several months and is found in $3 \%-25 \%$ of human populations in cross-sectional studies. ${ }^{70}$ Why the meningococcus causes invasive disease in a few individuals while colonizing the nasopharynx of many has been a fundamental question in meningococcal biology and pathogenesis. The absence of protective humoral bactericidal antibodies is a major host risk factor of invasive meningococcal disease. ${ }^{71}$ Infants and very young children are at highest risk of developing meningococcal disease before serum bactericidal antibodies develop and after maternal antibodies have waned. Additional factors for abnormal bactericidal activity in human sera include congenital or acquired immunoglobulin deficiencies and complement deficiencies. ${ }^{72-78}$
Other individual risk factors for meningococcal disease that have been found are active and passive smoking, ${ }^{79-82}$ concurrent respiratory infections, ${ }^{83}$ and crowding. ${ }^{84,85}$ The transmission of the meningococcus is clearly elevated in close contact ${ }^{84,86}$ and crowded living conditions (eg, barracks, dorms, pilgrimages). ${ }^{87,88}$ While the majority of invasive meningococcal cases are sporadic, a total of 69 outbreaks were identified in the US between mid 1994 and mid 2002, most of which were serogroup $\mathrm{C}$ outbreaks occurring in both the community and in institutional settings, such as nursing homes, schools, and colleges ${ }^{89}$ In addition, climatic conditions change the risk of invasive meningococcal disease. While meningococcal disease occurs year round, the majority of cases occur during the winter and early spring. ${ }^{11}$ In the meningitis belt in sub-Saharan Africa, epidemics usually occur in the dry season between March and April when it is hot, arid, and dusty, and last until the rainy season. ${ }^{16-18}$

\section{New vaccines for prevention}

An ideal vaccine for prevention of meningococcal disease would be effective against the invasive serogroups of meningococci and would elicit long-lasting immunity in all age groups, especially infants, children, and adolescents. Meningococcal polysaccharide vaccines for A, C, Y, and W-135 have been available since the 1970s and 1980s. However, they have been or are being replaced in routine use by polysaccharide-protein conjugate vaccines. Meningococcal polysaccharides alone elicit a poor immunologic response in infants and toddlers and the serum antibody response is generally short-lived, and even in older children and adults the protective response lasts approximately 5 years. In addition, the serogroup $\mathrm{C}$ and $\mathrm{A}$ polysaccharide vaccines have been shown to induce a hyporesponsive state to repeated meningococcal $\mathrm{C}$ or A polysaccharide administration. ${ }^{90}$

The immunogenicity of the meningococcal polysaccharide (shift from a T-independent to a T-dependent immune response) can be greatly improved by conjugation with a protein carrier (diphtheria or tetanus toxoid). Meningococcal serogroup C conjugate vaccines were first introduced in 1999 in the UK. They produced a dramatic decrease in the number of deaths and cases of invasive serogroup $\mathrm{C}$ meningococcal disease, as well as a $66 \%$ reduction in the carriage of $N$. meningitidis. ${ }^{69}$ The remarkable herd immunity effect of these conjugate vaccines through preventing acquisition and transmission accounts for about $50 \%$ of their effectiveness. ${ }^{69,91,92}$ Following the success of the meningococcal group $\mathrm{C}$ conjugate vaccine in circumventing the problems of the plain polysaccharide vaccine in the $\mathrm{UK},{ }^{69}$ tetravalent conjugate vaccines 
incorporating capsular groups A, C, Y, and W-135, and recently a bivalent $\mathrm{C}, \mathrm{Y}$ conjugate, covalently linked to tetanus or diphtheria toxoid, have been developed and are in clinical use. ${ }^{93}$ In May 2005, the US Centers for Disease Control and Prevention Advisory Committee on Immunization Practices recommended the first quadrivalent meningococcal conjugate vaccine for routine use in all US adolescents for protection against serogroups $\mathrm{A}, \mathrm{C}, \mathrm{W}-135$, and $\mathrm{Y}^{5}$ While the first quadrivalent conjugate vaccines were shown to have very high efficiency at generating protective bactericidal antibody titers, the overall population impact of the vaccine in the US was difficult to determine due to the falling incidence of disease and the initial low vaccine uptake. ${ }^{94}$ Other tetravalent and bivalent meningococcal conjugate vaccines are now licensed ${ }^{95}$ and the current age range of licensure approval is 2-55 years, with licensure for young children and infants approved by the US Food and Drug Administration for the C, Y, Haemophilus influenzae type b conjugate.

Even though the generalized use of the quadrivalent conjugate vaccine would be ideal, the cost of the vaccine has made these vaccines unaffordable for routine use in developing countries. The Meningitis Vaccine Project, a partnership between the World Health Organization and the Program for Appropriate Technology in Health, aims to eliminate epidemics of invasive meningococcal disease in sub-Saharan Africa and has developed a serogroup A-specific vaccine at an affordable price $(<50$ cents per dose). ${ }^{96,97}$ The vaccine, named MenAfriVac, was prequalified by the World Health Organization in June $2010 .{ }^{98}$ Mass vaccination campaigns began in December 2010 in Burkina Faso and are underway in other parts of the meningitis belt. ${ }^{98,99}$ This is an important public health priority to reduce the incidence of serogroup A meningococcal disease in this region, which has been so devastated by epidemics due to this serogroup.

Serogroup B polysaccharide of $N$. meningitidis is not included in the quadrivalent meningococcal conjugate vaccines due to the structural homology between the capsular polysaccharide and human antigens, including the human neural cell adhesion molecule. ${ }^{22,100}$ Efforts to develop a serogroup B-specific vaccine have used outer membrane vesicles and/or targeted relatively conserved and antigenic meningococcal outer membrane proteins. Progress is being made in the development of these vaccines. ${ }^{101}$

\section{Conclusion}

The human bacterial pathogen Neisseria meningitidis remains a serious worldwide health threat, but progress is being made toward the control of meningococcal infections. The incidence of meningococcal disease has decreased in developed countries in the last decade due at least in part to the new meningococcal polysaccharide-protein conjugate vaccines' effect against serogroups C, Y, W-135; and a serogroup A meningococcal conjugate vaccine is now being introduced into sub-Saharan Africa, a region with the highest rates of meningococcal disease. However, meningococcal disease is characterized by fluctuations in incidence and shifts in serogroups and genotypes. The basis for the dynamic epidemiology of meningococcal disease is not completely understood. Continued surveillance is essential in detecting, understanding, and predicting the changes in the epidemiology of meningococcal disease. Active surveillance for serogroupspecific and genotype-specific invasive disease allows for close monitoring of trends in meningococcal disease over time. A detailed understanding of meningococcal disease in communities will affect recommendations for current or future vaccines or other prevention strategies. Meningococcal vaccines that are effective and affordable against invasive strains, elicit long-lasting immunity in all age groups, and provide significant herd immunity will allow the development of strategies for the global elimination of meningococcal disease.

\section{Disclosure}

The authors report no conflicts of interest in this work.

\section{References}

1. Rouphael NG, Stephens DS. Neisseria meningitidis: biology, microbiology, and epidemiology. Methods Mol Biol. 2012;799:1-20.

2. Rosenstein NE, Perkins BA, Stephens DS, Popovic T, Hughes JM. Meningococcal disease. N Engl J Med. 2001;344(18):1378-1388.

3. Goldacre MJ, Roberts SE, Yeates D. Case fatality rates for meningococcal disease in an English population, 1963-1998: database study. BMJ. 2003; 327(7415):596-597.

4. Tunkel AR, Hartman BJ, Kaplan SL, et al. Practice guidelines for the management of bacterial meningitis. Clin Infect Dis. 2004;39(9): $1267-1284$.

5. Bilukha OO, Rosenstein N. Prevention and control of meningococcal disease. Recommendations of the Advisory Committee on Immunization Practices (ACIP). MMWR Recomm Rep. 2005;54(RR-7):1-21.

6. Oster P, Lennon D, O'Hallahan J, et al. MeNZB: a safe and highly immunogenic tailor-made vaccine against the New Zealand Neisseria meningitidis serogroup B disease epidemic strain. Vaccine. 2005; 23(17-18):2191-2196.

7. Rodriguez AP, Dickinson F, Baly A, Martinez R. The epidemiological impact of antimeningococcal B vaccination in Cuba. Mem Inst Oswaldo Cruz. 1999;94(4):433-440.

8. Galloway Y, Stehr-Green P, McNicholas A, O'Hallahan J. Use of an observational cohort study to estimate the effectiveness of the New Zealand group B meningococcal vaccine in children aged under 5 years. Int J Epidemiol. 2009;38(2):413-418.

9. Brehony C, Jolley KA, Maiden MC. Multilocus sequence typing for global surveillance of meningococcal disease. FEMS Microbiol Rev. 2007;31(1):15-26. 
10. Harrison LH, Trotter CL, Ramsay ME. Global epidemiology of meningococcal disease. Vaccine. 2009;27 Suppl 2:B51-B63.

11. Rosenstein NE, Perkins BA, Stephens DS, et al. The changing epidemiology of meningococcal disease in the United States, 1992-1996. J Infect Dis. 1999;180(6):1894-1901.

12. Cohn AC, MacNeil JR, Harrison LH, et al. Changes in Neisseria meningitidis disease epidemiology in the United States, 1998-2007: implications for prevention of meningococcal disease. Clin Infect Dis. 2010;50(2):184-191.

13. Harrison LH. Epidemiological profile of meningococcal disease in the United States. Clin Infect Dis. 2010;50 Suppl 2:S37-S44.

14. Harrison LH, Shutt KA, Schmink SE, et al. Population structure and capsular switching of invasive Neisseria meningitidis isolates in the pre-meningococcal conjugate vaccine era - United States, 2000-2005. J Infect Dis. 2010;201(8):1208-1224.

15. Caugant DA, Nicolas P. Molecular surveillance of meningococcal meningitis in Africa. Vaccine. 2007;25 Suppl 1:A8-A11.

16. Molesworth AM, Cuevas LE, Connor SJ, Morse AP, Thomson MC. Environmental risk and meningitis epidemics in Africa. Emerg Infect Dis. 2003;9(10):1287-1293.

17. Greenwood BM, Bradley AK, Wall RA. Meningococcal disease and season in sub-Saharan Africa. Lancet. 1985;2(8459):829-830.

18. Sultan B, Labadi K, Guegan JF, Janicot S. Climate drives the meningitis epidemics onset in west Africa. PLoS Med. 2005;2(1):e6.

19. Diermayer M, Hedberg K, Hoesly F, et al. Epidemic serogroup B meningococcal disease in Oregon: the evolving epidemiology of the ET-5 strain. JAMA. 1999;281(16):1493-1497.

20. Racloz VN, Luiz SJ. The elusive meningococcal meningitis serogroup: a systematic review of serogroup B epidemiology. BMC Infect Dis. 2010;10:175.

21. Swartley JS, Marfin AA, Edupuganti S, et al. Capsule switching of Neisseria meningitidis. Proc Natl Acad Sci U S A. 1997;94(1): 271-276.

22. Troy FA 2nd. Polysialylation: from bacteria to brains. Glycobiology. 1992;2(1):5-23.

23. Sotolongo F, Campa C, Casanueva V, et al. Cuban meningococcal BC vaccine: experiences and contributions from 20 years of application. MEDICC Rev. 2008;9(1):16-22.

24. de Moraes JC, Perkins BA, Camargo MC, et al. Protective efficacy of a serogroup B meningococcal vaccine in Sao Paulo, Brazil. Lancet. 1992;340(8827):1074-1078

25. Milagres LG, Ramos SR, Sacchi CT, et al. Immune response of Brazilian children to a Neisseria meningitidis serogroup B outer membrane protein vaccine: comparison with efficacy. Infect Immun. 1994;62(10): 4419-4424.

26. Noronha CP, Struchiner CJ, Halloran ME. Assessment of the direct effectiveness of BC meningococcal vaccine in Rio de Janeiro, Brazil: a case-control study. Int J Epidemiol. 1995;24(5):1050-1057.

27. Richmond PC, Marshall HS, Nissen MD, et al. Safety, immunogenicity, and tolerability of meningococcal serogroup B bivalent recombinant lipoprotein 2086 vaccine in healthy adolescents: a randomised, singleblind, placebo-controlled, phase 2 trial. Lancet Infect Dis. 2012;12(8): 597-607.

28. Santolaya ME, O'Ryan ML, Valenzuela MT, et al. Immunogenicity and tolerability of a multicomponent meningococcal serogroup B (4CMenB) vaccine in healthy adolescents in Chile: a phase $2 b / 3$ randomised, observer-blind, placebo-controlled study. Lancet. 2012;379(9816): 617-624.

29. Gossger N, Snape MD, Yu LM, et al. Immunogenicity and tolerability of recombinant serogroup B meningococcal vaccine administered with or without routine infant vaccinations according to different immunization schedules: a randomized controlled trial. JAMA. 2012; 307(6):573-582.

30. Cohn AC, Messonnier NE. Inching toward a serogroup B meningococcal vaccine for infants. JAMA. 2012;307(6):614-615.

31. Stephens DS. Prevention of serogroup B meningococcal disease. Lancet. 2012;379(9816):592-594.
32. Control ECfDPa. Annual epidemiological report 2011-Reporting on 2009 surveillance data and 2010 epidemic intelligence data. Euro Surveill. 2011;16(45):20012.

33. Jackson LA, Wenger JD. Laboratory-based surveillance for meningococcal disease in selected areas, United States, 1989-1991. MMWR CDC Surveill Summ. 1993;42(2):21-30.

34. Kellerman SE, McCombs K, Ray M, et al. Genotype-specific carriage of Neisseria meningitidis in Georgia counties with hyper- and hyposporadic rates of meningococcal disease. J Infect Dis. 2002; 186(1):40-48.

35. Clark TA, Stern E, Pondo T, et al. The effect of quadrivalent (A, C, Y, W-135) meningococcal conjugate vaccine on serogroup-specific carriage of Neisseria meningitidis. Presented at the 16th International Pathogenic Neissera conference, Rotterdam, The Netherlands, September 7-12, 2008.

36. Abad R, Agudelo CI, Brandileone MC, et al. Molecular characterization of invasive serogroup Y Neisseria meningitidis strains isolated in the Latin America region. J Infect. 2009;59(2):104-114.

37. Whitney AM, Coulson GB, von Gottberg A, et al. Genotypic comparison of invasive Neisseria meningitidis serogroup Y isolates from the United States, South Africa, and Israel, isolated from 1999 through 2002. J Clin Microbiol. 2009;47(9):2787-2793.

38. Tsang RS, Henderson AM, Cameron ML, et al. Genetic and antigenic analysis of invasive serogroup Y Neisseria meningitidis isolates collected from 1999 to 2003 in Canada. J Clin Microbiol. 2007;45(6): $1753-1758$.

39. Materu S, Cox HS, Isaakidis $P$, et al. Serogroup X in meningococcal disease, Western Kenya. Emerg Infect Dis. 2007;13(6):944-945.

40. Gagneux $\mathrm{S}$, Wirth T, Hodgson A, et al. Clonal groupings in serogroup $X$ Neisseria meningitidis. Emerg Infect Dis. 2002;8(5):462-466.

41. Gagneux SP, Hodgson A, Smith TA, et al. Prospective study of a serogroup X Neisseria meningitidis outbreak in northern Ghana. J Infect Dis. 2002;185(5):618-626.

42. Boisier P, Nicolas P, Djibo S, et al. Meningococcal meningitis: unprecedented incidence of serogroup X-related cases in 2006 in Niger. Clin Infect Dis. 2007;44(5):657-663.

43. Delrieu I, Yaro S, Tamekloe TA, et al. Emergence of epidemic Neisseria meningitidis serogroup $\mathrm{X}$ meningitis in Togo and Burkina Faso. PLoS One. 2011;6(5):e19513.

44. Aguilera JF, Perrocheau A, Meffre C, Hahne S, Group WW. Outbreak of serogroup W135 meningococcal disease after the Hajj pilgrimage, Europe, 2000. Emerg Infect Dis. 2002;8(8):761-767.

45. Raghunathan PL, Jones JD, Tiendrebeogo SR, et al. Predictors of immunity after a major serogroup W-135 meningococcal disease epidemic, Burkina Faso, 2002. J Infect Dis. 2006;193(5):607-616.

46. Mayer LW, Reeves MW, Al-Hamdan N, et al. Outbreak of W135 meningococcal disease in 2000: not emergence of a new W135 strain but clonal expansion within the electophoretic type-37 complex. J Infect Dis. 2002;185(11):1596-1605.

47. Stephens DS, Greenwood B, Brandtzaeg P. Epidemic meningitis, meningococcaemia, and Neisseria meningitidis. Lancet. 2007;369(9580): 2196-2210.

48. Liu TY, Gotschlich EC, Dunne FT, Jonssen EK. Studies on the meningococcal polysaccharides. II. Composition and chemical properties of the group B and group C polysaccharide. J Biol Chem. 1971;246(15): 4703-4712.

49. Bhattacharjee AK, Jennings HJ, Kenny CP, Martin A, Smith IC. Structural determination of the polysaccharide antigens of Neisseria meningitidis serogroups Y, W-135, and BO1. Can J Biochem. 1976; $54(1): 1-8$.

50. Liu TY, Gotschlich EC, Jonssen EK, Wysocki JR. Studies on the meningococcal polysaccharides. I. Composition and chemical properties of the group A polysaccharide. J Biol Chem. 1971;246(9): 2849-2858.

51. Bundle DR, Jennings HJ, Kenny CP. Studies on the group-specific polysaccharide of Neisseria meningitidis serogroup X and an improved procedure for its isolation. J Biol Chem. 1974;249(15):4797-4801. 
52. Davidsen T, Tonjum T. Meningococcal genome dynamics. Nat Rev Microbiol. 2006;4(1):11-22.

53. Hill DJ, Griffiths NJ, Borodina E, Virji M. Cellular and molecular biology of Neisseria meningitidis colonization and invasive disease. Clin Sci (Lond). 2010;118(9):547-564.

54. Kriz P, Giorgini D, Musilek M, Larribe M, Taha MK. Microevolution through DNA exchange among strains of Neisseria meningitidis isolated during an outbreak in the Czech Republic. Res Microbiol. 1999;150(4): 273-280.

55. van der Ende A, Hopman CT, Dankert J. Deletion of porA by recombination between clusters of repetitive extragenic palindromic sequences in Neisseria meningitidis. Infect Immun. 1999;67(6): 2928-2934.

56. Berrington AW, Tan YC, Srikhanta Y, et al. Phase variation in meningococcal lipooligosaccharide biosynthesis genes. FEMS Immunol Med Microbiol. 2002;34(4):267-275.

57. Hammerschmidt S, Muller A, Sillmann H, et al. Capsule phase variation in Neisseria meningitidis serogroup B by slipped-strand mispairing in the polysialyltransferase gene $($ siaD): correlation with bacterial invasion and the outbreak of meningococcal disease. Mol Microbiol. 1996;20(6): $1211-1220$.

58. Hammerschmidt S, Hilse R, van Putten JP, et al. Modulation of cell surface sialic acid expression in Neisseria meningitidis via a transposable genetic element. EMBO J. 1996;15(1):192-198.

59. Cahoon LA, Seifert HS. Focusing homologous recombination: pilin antigenic variation in the pathogenic Neisseria. Mol Microbiol. 2011; 81(5):1136-1143.

60. Helm RA, Seifert HS. Frequency and rate of pilin antigenic variation of Neisseria meningitidis. J Bacteriol. 2010;192(14):3822-3823.

61. Andrews TD, Gojobori T. Strong positive selection and recombination drive the antigenic variation of the PilE protein of the human pathogen Neisseria meningitidis. Genetics. 2004;166(1):25-32.

62. Budroni S, Siena E, Hotopp JC, et al. Neisseria meningitidis is structured in clades associated with restriction modification systems that modulate homologous recombination. Proc Natl Acad Sci U SA. 2011;108(11): 4494-4499.

63. Tzeng YL, Datta A, Ambrose KD, et al. The MisR/MisS two-component regulatory system influences inner core structure and immunotype of lipooligosaccharide in Neisseria meningitidis. J Biol Chem. 2004;279: 35053-35062.

64. Alcala B, Arreaza L, Salcedo C, et al. Capsule switching among $\mathrm{C}: 2 \mathrm{~b}:$ P1.2,5 meningococcal epidemic strains after mass immunization campaign, Spain. Emerg Infect Dis. 2002;8(12):1512-1514.

65. Simoes MJ, Cunha M, Almeida F, Furtado C, Brum L. Molecular surveillance of Neisseria meningitidis capsular switching in Portugal, 2002-2006. Epidemiol Infect. 2009;137(2):161-165.

66. Stefanelli P, Fazio C, Neri A, Sofia T, Mastrantonio P. First report of capsule replacement among electrophoretic type 37 Neisseria meningitidis strains in Italy. J Clin Microbiol. 2003;41(12):5783-5786.

67. Kertesz DA, Coulthart MB, Ryan JA, Johnson WM, Ashton FE. Serogroup B, electrophoretic type 15 Neisseria meningitidis in Canada. J Infect Dis. 1998;177(6):1754-1757.

68. Tsang RS, Law DK, Tyler SD, et al. Potential capsule switching from serogroup Y to B: The characterization of three such Neisseria meningitidis isolates causing invasive meningococcal disease in Canada. Can J Infect Dis Med Microbiol. 2005;16(3):171-174.

69. Balmer P, Borrow R, Miller E. Impact of meningococcal C conjugate vaccine in the UK. J Med Microbiol. 2002;51(9):717-722.

70. Stephens DS. Uncloaking the meningococcus: dynamics of carriage and disease. Lancet. 1999;353(9157):941-942.

71. Goldschneider I, Gotschlich EC, Artenstein MS. Human immunity to the meningococcus. I. The role of humoral antibodies. J Exp Med. 1969; 129(6):1307-1326.

72. Bishof NA, Welch TR, Beischel LS. C4B deficiency: a risk factor for bacteremia with encapsulated organisms. J Infect Dis. 1990;162(1): $248-250$.
73. Hogasen K, Michaelsen T, Mellbye OJ, Bjune G. Low prevalence of complement deficiencies among patients with meningococcal disease in Norway. Scand J Immunol. 1993;37(4):487-489.

74. Westendorp RG, Langermans JA, de Bel CE, et al. Release of tumor necrosis factor: an innate host characteristic that may contribute to the outcome of meningococcal disease. J Infect Dis. 1995;171(4): $1057-1060$.

75. Nadel S, Newport MJ, Booy R, Levin M. Variation in the tumor necrosis factor-alpha gene promoter region may be associated with death from meningococcal disease. J Infect Dis. 1996;174(4):878-880.

76. Westendorp RG, Langermans JA, Huizinga TW, et al. Genetic influence on cytokine production and fatal meningococcal disease. Lancet. 1997;349(9046):170-173.

77. Vermont CL, de Groot R, Hazelzet JA. Bench-to-bedside review: genetic influences on meningococcal disease. Crit Care. 2002;6(1):60-65.

78. Haralambous E, Dolly SO, Hibberd ML, et al. Factor H, a regulator of complement activity, is a major determinant of meningococcal disease susceptibility in UK Caucasian patients. Scand J Infect Dis. 2006; 38(9):764-771.

79. Haneberg B, Tonjum T, Rodahl K, Gedde-Dahl TW. Factors preceding the onset of meningococcal disease, with special emphasis on passive smoking, symptoms of ill health. NIPH Ann. 1983;6(2):169-173.

80. Coen PG, Tully J, Stuart JM, et al. Is it exposure to cigarette smoke or to smokers which increases the risk of meningococcal disease in teenagers? Int J Epidemiol. 2006;35(2):330-336.

81. Fischer M, Hedberg K, Cardosi P, et al. Tobacco smoke as a risk factor for meningococcal disease. Pediatr Infect Dis J. 1997;16(10):979-983.

82. Yusuf HR, Rochat RW, Baughman WS, et al. Maternal cigarette smoking and invasive meningococcal disease: a cohort study among young children in metropolitan Atlanta, 1989-1996. Am J Public Health. 1999;89(5):712-717.

83. Cartwright KA, Jones DM, Smith AJ, et al. Influenza A and meningococcal disease. Lancet. 1991;338(8766):554-557.

84. Baker M, McNicholas A, Garrett N, et al. Household crowding a major risk factor for epidemic meningococcal disease in Auckland children. Pediatr Infect Dis J. 2000;19(10):983-990.

85. Deutch S, Labouriau R, Schonheyeder HC, et al. Crowding as a risk factor of meningococcal disease in Danish preschool children: a nationwide population-based case-control study. Scand J Infect Dis. 2004;36(1):20-23.

86. Olcen P, Kjellander J, Danielsson D, Lindquist BL. Epidemiology of Neisseria meningitidis; prevalence and symptoms from the upper respiratory tract in family members to patients with meningococcal disease. Scand J Infect Dis. 1981;13(2):105-109.

87. Hudson PJ, Vogt RL, Heun EM, et al. Evidence for school transmission of Neisseria meningitidis during a Vermont outbreak. Pediatr Infect Dis. 1986;5(2):213-217.

88. Neal KR, Nguyen-Van-Tam JS, Jeffrey N, et al. Changing carriage rate of Neisseria meningitidis among university students during the first week of term: cross sectional study. BMJ. 2000;320(7238): 846-849.

89. Brooks R, Woods CW, Benjamin DK Jr, Rosenstein NE. Increased case-fatality rate associated with outbreaks of Neisseria meningitidis infection, compared with sporadic meningococcal disease, in the United States, 1994-2002. Clin Infect Dis. 2006;43(1):49-54.

90. MacDonald NE, Halperin SA, Law BJ, et al. Induction of immunologic memory by conjugated vs plain meningococcal $\mathrm{C}$ polysaccharide vaccine in toddlers: a randomized controlled trial. JAMA. 1998;280(19): $1685-1689$.

91. Stephens DS. Protecting the herd: the remarkable effectiveness of the bacterial meningitis polysaccharide-protein conjugate vaccines in altering transmission dynamics. Trans Am Clin Climatol Assoc. 2011; 122:115-123.

92. Maiden MC, Ibarz-Pavon AB, Urwin R, et al. Impact of meningococcal serogroup $\mathrm{C}$ conjugate vaccines on carriage and herd immunity. $J$ Infect Dis. 2008;197(5):737-743. 
93. Harrison LH, Mohan N, Kirkpatrick P. Meningococcal group A, C, Y and W-135 conjugate vaccine. Nat Rev Drug Discov. 2010;9(6):429-430.

94. Pichichero ME. Meningococcal conjugate vaccines. Expert Opin Biol Ther. 2005;5(11):1475-1489.

95. Halperin SA, Gupta A, Jeanfreau R, et al. Comparison of the safety and immunogenicity of an investigational and a licensed quadrivalent meningococcal conjugate vaccine in children $2-10$ years of age. Vaccine. 2010;28(50):7865-7872.

96. Marc LaForce F, Ravenscroft N, Djingarey M, Viviani S. Epidemic meningitis due to Group A Neisseria meningitidis in the African meningitis belt: a persistent problem with an imminent solution. Vaccine. 2009;27 Suppl 2:B13-B19.

97. Bishai DM, Champion C, Steele ME, Thompson L. Product development partnerships hit their stride: lessons from developing a meningitis vaccine for Africa. Health Aff (Millwood). 2011;30(6):1058-1064.
98. Frasch C, Preziosi MP, Laforce FM. Development of a group A meningococcal conjugate vaccine, MenAfriVac (TM). Hum Vaccin Immunother. 2012;8(6). [Epub ahead of print.]

99. Djingarey MH, Barry R, Bonkoungou M, et al. Effectively introducing a new meningococcal A conjugate vaccine in Africa: the Burkina Faso experience. Vaccine. 2012;30 Suppl 2:B40-B45.

100. McCoy RD, Vimr ER, Troy FA. CMP-NeuNAc:poly-alpha-2,8-sialosyl sialyltransferase and the biosynthesis of polysialosyl units in neural cell adhesion molecules. J Biol Chem. 1985;260(23):12695-12699.

101. Holst J. Strategies for development of universal vaccines against meningococcal serogroup B disease: the most promising options and the challenges evaluating them. Hum Vaccin. 2007;3(6):290-294.

102. Dolan-Livengood JM, Miller YK, Martin LE, Urwin R, Stephens DS. Genetic basis for nongroupable Neisseria meningitidis. J Infect Dis. 2003;187(10):1616-1628.
Clinical Epidemiology

\section{Publish your work in this journal}

Clinical Epidemiology is an international, peer-reviewed, open access journal focusing on disease and drug epidemiology, identification of risk factors and screening procedures to develop optimal preventative initiatives and programs. Specific topics include: diagnosis, prognosis, treatment, screening, prevention, risk factor modification, systematic

Submit your manuscript here: http://www.dovepress.com/clinical-epidemiology-journa

\section{Dovepress}

reviews, risk \& safety of medical interventions, epidemiology \& biostatical methods, evaluation of guidelines, translational medicine, health policies \& economic evaluations. The manuscript management system is completely online and includes a very quick and fair peer-review system, which is all easy to use. 